\title{
Boronolectin with Divergent Fluorescent Response Specific for Free Sialic Acid.
}

\author{
Stephan M. Levonis, Milton J. Kiefel, and Todd A. Houston* \\ Received (in $X X X, X X X)$ Xth $X X X X X X X X X 200 X$, Accepted $X$ th $X X X X X X X X X 200 X$ \\ ${ }_{5}$ First published on the web Xth $X X X X X X X X X 200 X$ \\ DOI: $10.1039 / \mathbf{b 0 0 0 0 0 0 x}$
}

\begin{abstract}
A fluorescent boronate receptor with a unique response to free sialic acid has been developed. This diveregent response system may find use in design of other fluorophores to discriminate 10 between structurally similar analytes.
\end{abstract}

Boronic acid-based carbohydrate sensors have been developed for a variety of biological applications from blood glucose monitoring, including glucose-responsive contact lenses, to "boronolectins" for cell-surface carbohydrate identification. ${ }^{1}$ The 15 reversible esterification of boronates by carbohydrates in aqueous solution can be sensitively monitored either by fluorescence quenching, as first demonstrated by $\mathrm{Czarnik}^{2}$, or through fluorescence signal increase by elimination of internal quenching mechanisms such as photon-induced electron transfer (PET), as 20 first reported by Shinkai. ${ }^{3}$ Recently, James has developed an aniline-based system (1) that responds to monosaccharide binding with fluorescence signal enhancement via both locally excited (LE) and twisted internal charge transfer (TICT) states. ${ }^{4}$ The binding of sugar diols by the boron effectively turns fluorescence 25 "on", i.e.-there is an increase in fluorescence intensity $\left(\mathrm{I}>\mathrm{I}_{\mathrm{o}}\right)$. In order to compete with natural lectins for carbohydrate identification, boronolectins that are highly selective for particular monosaccharide ligands must be developed.

Sialic acids (e.g.- Neu5Ac) are important carbohydrates 30 ubiquitous to mammalian cell surfaces. Serum levels of sialic acid can be utilized as a biological marker of a cancerous state. ${ }^{5}$ Free sialic acid has been shown to be a superior marker for carcinoma of the uterine cervix and genitourinary malignancies when compared to total sialic acid and lipid-bound sialic acid 35 measurements. ${ }^{6}$ Improved fluorescent sensing of free sialic acid within a sample could enable the enhanced detection of malignancies and other diseases involving aberrant sialic acid levels. ${ }^{7}$ Elevated free sialic acid levels in serum can serve as a marker for alcohol abuse as well. ${ }^{8}$ Most methods to identify free 40 sialic acid in biological samples require the use of sample purification steps. By developing a fluorophore that responds uniquely to sialic acid over other biological components, direct measurement of this monosaccharide in biological samples would become possible.

45 Here, we report the design of a bis(boronate) receptor (2) for free sialic acid that contains both an "on" (I $>\mathrm{I}_{\mathrm{o}}$ ) and "off" $\left(\mathrm{I}<\mathrm{I}_{0}\right)$ switch with regard to fluorescent signal from the aniline moiety upon analyte binding (Fig. 1). Most common monosaccharides cannot span both boronates and thus should 50 not significantly modulate the fluorescent output of $\mathbf{2}$, binding weakly to both the "on" and "off" sites resulting in little change in fluorescence response. The low affinity of hexoses for monoboronates means simple sugars shouldn't saturate the receptor (forming a 2:1 diester and turning fluorescence "off") 55 until very high concentrations of carbohydrate. Importantly, this receptor was designed to respond via fluorescence quenching when both boron sites are esterified as the "off" switch is a boronate conjugated within the aniline fluorophore. Due to the enhanced affinity of molecules that ${ }_{60}$ can serve as divalent ligands, such compounds should cause significant fluorescence quenching even in the presence of molecules that can bind only one boronate and would potentially cause fluorescence to increase. Such a receptor system would be unprecedented in the field and an advance ${ }_{65}$ toward improving the sensitivity of determining free sialic acid levels in biological samples by effectively "silencing" competing sugars.

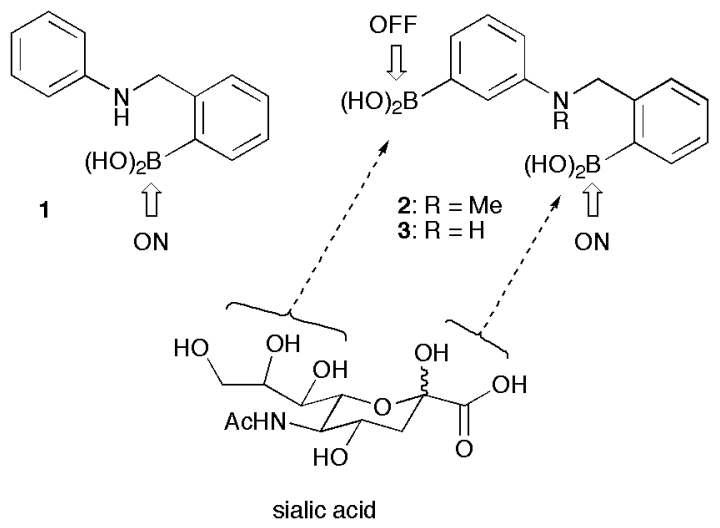

Fig. 1 Boronolectin designed to bind sialic acid

70 Sialic acid has two unique structural features that can be targeted with a diboronate receptor: (1) an extended glycerol side chain and (2) an $\alpha$-hydroxyacid-type arrangement of the hemiketal at the anomeric position. Previous work on sialic acidmonoboronate interactions ${ }^{9}$ have shown that boron binding shifts 75 from the glycerol tail to the anomeric centre as $\mathrm{pH}$ decreases. ${ }^{10}$ The earliest fluorescent, boronate-based sialic acid receptors of Shinkai ${ }^{11}$ and Smith \& Taylor ${ }^{12}$ used electrostatic interactions to bind the carboxylate of the sugar. By using a boronate to target this functional group, receptor 2 should be less affected by 80 competing anions in the biological milieu. This bis(boronate) receptor was readily constructed by sequential reductive aminations of 2-formylphenylboronic acid first with 3aminophenylboronic acid/ $\mathrm{NaBH}_{4}$ to yield $3^{13}(76 \%)$ followed by methylation with formaldehyde/ $\mathrm{NaBH}_{4}(30 \%)$ to furnish $2{ }^{\ddagger}$ Both ${ }_{85} \mathbf{2}$ and $\mathbf{3}$ were purified by column chromatography on neutral alumina.

Boronate binding of neutral monosaccharides tends to be favoured at $\mathrm{pH}$ values approaching that of the ligand. ${ }^{14}$ Using Shinkai's glucose receptor ${ }^{15}$, we first demonstrated that $\alpha$ 90 hydroxyacid moieties of tartrate can be targeted with fluorescent bis(boronates) ${ }^{16}$ and subsequent work by James has shown that multivalent hydroxyacid-boron binding is favoured at acidic $\mathrm{pH}$ in this system. ${ }^{17}$ As such, we tested the binding of $2(33 \mu \mathrm{M})$ with various monosaccharides in both acidic $(\mathrm{pH}$ 6.2) and basic $(\mathrm{pH}$ 
7.8) environments (100 $\mathrm{mM}$ aq. phosphate buffer/MeOH 2:1). As can be seen in Fig. 2, selective response of $\mathbf{2}$ to sialic acid was best at the lower $\mathrm{pH}$. Neutral monosaccharides glucose, galactose, mannose and ribose and the anionic sugar glucuronic 5 acid changed the fluorescence output of $\mathbf{2}$ very little at the lower $\mathrm{pH}$. Although ribose had the highest affinity at higher $\mathrm{pH}$, this decreased markedly at acidic $\mathrm{pH}$. Importantly, the $\alpha$-methyl sialoside gave a modest decrease but not to the degree of the free parent sugar. This data supports a divalent binding mechanism 10 involving esterification of both boronates in $\mathbf{2}$ by sialic acid (Scheme 1). This is further supported by low resolution, negative ion ESI-MS ( $m / z$ 579). Lactose, a potentially bidentate ligand, failed to reduce fluorescence of $\mathbf{2}$ at $\mathrm{pH} 6.2$ (data not shown). Crucially, titration of the receptor $\mathbf{2}$ with sialic acid in the ${ }_{15}$ presence of $50 \mathrm{mM}$ glucose gave closely similar results to titration with sialic acid alone. Glucose levels in the blood serum of non-diabetic adults are in the range of 4-7 mM, but can reach $50 \mathrm{mM}$ in diabetics, while free sialic acid levels in the blood are much lower (0.15-0.2 mM). Thus, divergent response systems 20 like the one described here may be developed to identify sialic acid levels in unmodified biological samples without enzymic conversion of glucose a priori.
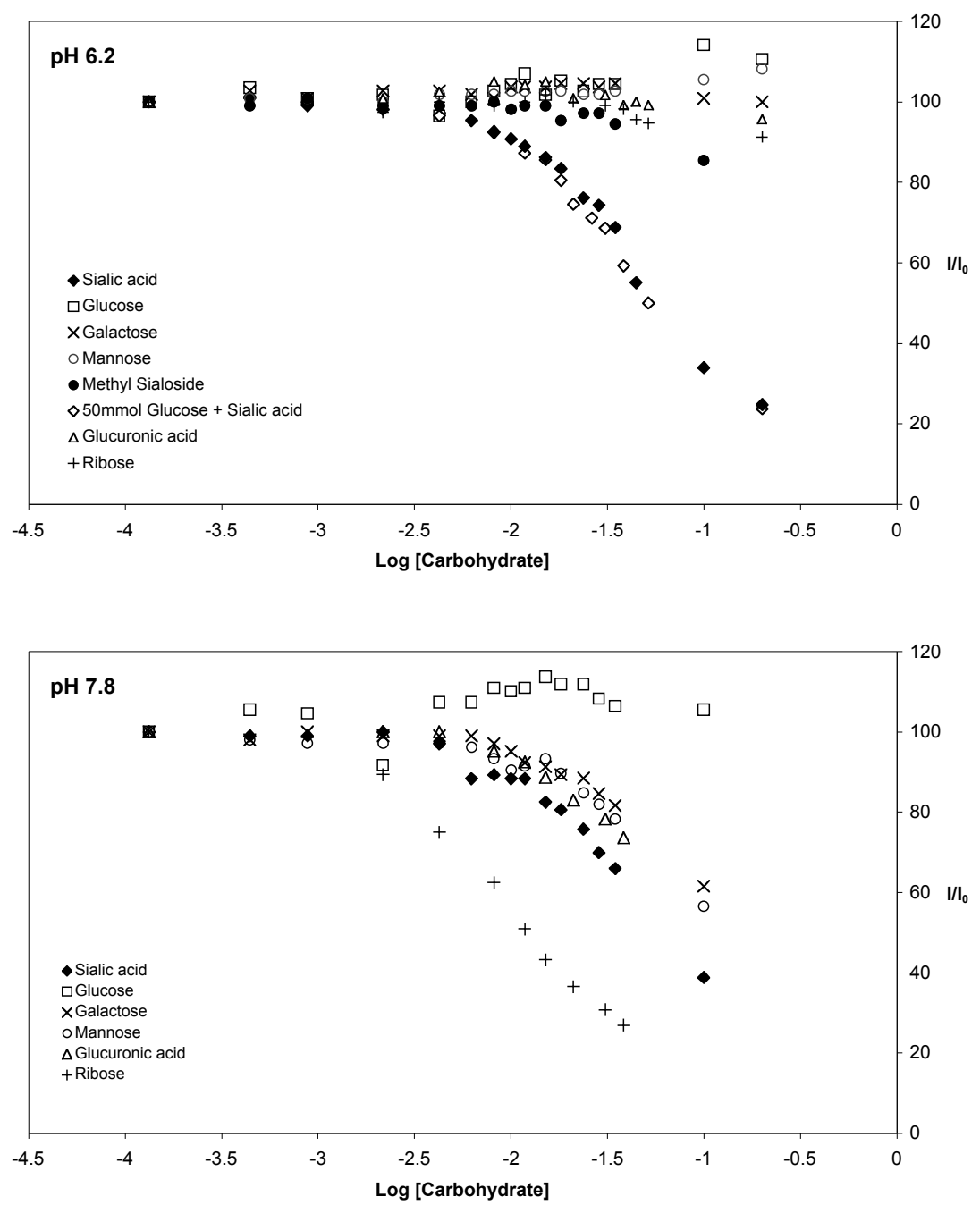

Fig. 2 Fluorescence of Compound $2(33 \mu \mathrm{M})$ in 2:1 $100 \mathrm{mM}$ aq. Phosphate/MeOH (Ex. $315 \mathrm{~nm}$, Em. $388 \mathrm{~nm})$

The importance of the tertiary amine in $\mathbf{2}$ is demonstrated by the fluorescent response of $\mathbf{3}$ toward the same monosaccharides. While interaction of $\mathbf{3}$ with sialic acid still causes the greatest fluorescent decrease at $\mathrm{pH}$ 6.2, other sugars caused significant 30 depression in the fluorescent output of this receptor. ${ }^{\dagger}$ This is likely due to trapping of the acyclic aldehyde form of the sugars through imine formation with the secondary amine (Scheme 1). This is supported by the fact that $m$-aminophenylboronic acid alone gives very similar results to $\mathbf{3}$. The meta-substitution in 35 receptor 2 restricts the ability of this molecule to bind simple monosaccharides through both boronates. Diboronates can readily bind glucose in a divalent sense through diols at $\mathrm{C} 1 / \mathrm{C} 2$ and $\mathrm{C} 4 / \mathrm{C} 6$ but this requires a convergent approach of the two boronates. Such an orientation is not available for compound 2. ${ }_{40}$ By binding weakly to both the "on" and "off" switches, glucose changes the overall fluorescence output very little (the small concentrations of each of the two complexes shown in Scheme 1 effectively cancel each other out: $\mathrm{I} \approx \mathrm{I}_{\mathrm{o}}$ ).

Previously, Shinkai reported a diboronate system that will give ${ }_{45}$ a CD response to glucose, but not its methyl glucoside. ${ }^{18}$ Additionally, we have shown previously that diboronates can give a fluorescent increase in the presence of one inositol epimer (chiro), but not the other ( $m y o$ ), an example of "stereospecific sensing". ${ }^{19}$ Our current work is complementary and potentially so powerful in that we have identified the framework to bind to a single monosaccharide (sialic acid) selectively and to signal that 
binding specifically in preference to other common monosaccharides. The divergent response of the fluorophore significantly dampens background signals from competing ligands. Only sialic acid causes fluorescent quenching of $\mathbf{2}$ to an 5 extent that it can be titrated. What remains is to extend conjugation in this system to improve sensitivity of detection. Preorganization of this ditopic receptor through conformational restriction can improve current affinity. ${ }^{20}$ Direct fluorescent measurement of free sialic acid levels in biological fluids will 10 improve the timeframe of analysis and obviate the need for sample preparation. This divergent response approach may also find use in other analytical techniques where detection among structurally similar analytes is required.

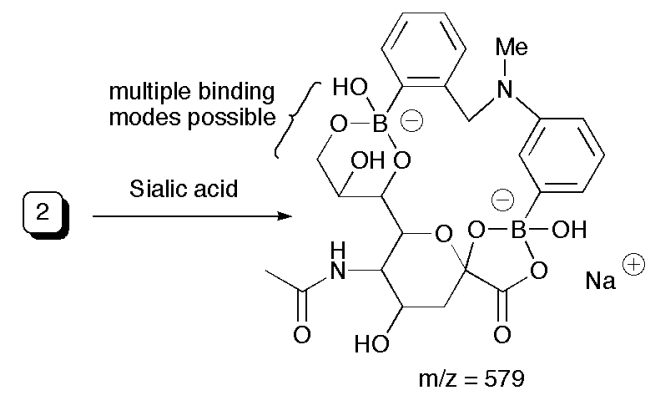<smiles>O=C(O)c1ccccc1CN(Cc1cccc(B2OC3OC(O)C(O)C(O)C3O2)c1)c1ccccc1</smiles>
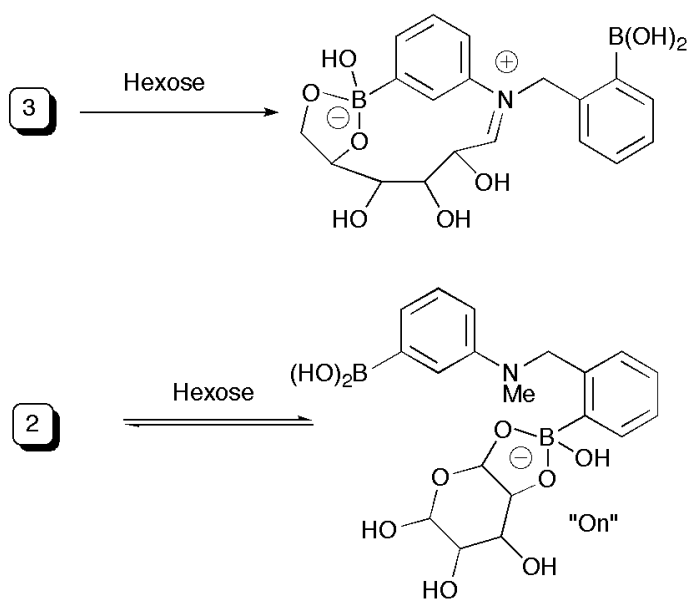

Scheme 1 Possible Monosaccharide Binding Mechanisms of 2 and 3. Only pyranoside forms shown.

This paper is dedicated to the inspiring work of Prof. Seiji Shinkai on the occasion of his $65^{\text {th }}$ birthday. His seminal contributions to the development of boron-based, fluorescent 20 carbohydrate receptors are unparalleled.

\section{Notes and references}

${ }^{a}$ Institute for Glycomics, Gold Coast Campus, Griffith University, QLD 4222, Australia. Fax: +617 5552 8098; Tel: +617 5552 7051; E-mail: t.houston@griffith.edu.au

$25 \dagger$ Electronic Supplementary Information (ESI) available: Fluorescence data for compound 3 at $\mathrm{pH} 6.2$. See DOI: $10.1039 / \mathrm{b} 000000 \mathrm{x} /$

\$ Data for compound 2:. ${ }^{1} \mathrm{H}-\mathrm{NMR}(300 \mathrm{MHz}, \mathrm{MeOD}): \delta 2.79(\mathrm{~s}, 3 \mathrm{H})$, $4.42(\mathrm{~s}, 2 \mathrm{H}), 6.92(\mathrm{~m}, 1 \mathrm{H}), 7.10(\mathrm{t}, 1 \mathrm{H}, J=2.7 \mathrm{~Hz}), 7.20(\mathrm{~m}, 4 \mathrm{H}), 7.35$ $(\mathrm{m}, 1 \mathrm{H}), 7.42(\mathrm{~m}, 1 \mathrm{H})$; HRMS (ESI) Calcd for $\mathrm{C}_{14} \mathrm{H}_{17} \mathrm{~B}_{2} \mathrm{NO}_{4}+\mathrm{Na}^{+}$: 30 306.1309, Found: 306.1302 .

1. T. D. James, and S. Shinkai, Top. Curr. Chem., 2002, 218, 159; R. Badugu, J. R. Lakowicz, and C. D. Geddes, Curr. Opin. Biotechnol., 2005, 16, 100; W. Yang, H. Fan, S. Gao, X. Gao, V. V. R. Karnati, W. Ni, W. B. Hooks, J. Carson, B. Weston, and B. Wang, Chem. Biol., 2004, 11, 439; J. Yan, H. Fang, and B. Wang, Med. Res. Rev., 2005, 25, 490; E. V. Anslyn, J. Org. Chem., 2007, 72, 687; H. S. Mader and O. S. Wolfbeis, Microchem. Acta, 2008, 162, 1; M. Bérubé, M. Dowlut, D. G. Hall, J. Org. Chem., 2008, 73, 6471.

40 2. J. Yoon, and A. W. Czarnik, J. Am. Chem. Soc., 1992, 114, 5874.

3. T. D. James, K. R. A. S. Samankumara, and S. Shinkai, Chem. Commun., 1994, 447.

4. L. I. Bosch, M. F. Mahon, and T. D. James, Tetrahedron Lett., 2004 , 45, 2859.

45 5. F. J. Krolikowski, K. Reuter, T. P. Waalkes, S. M. Sieber, and R. H. Adamson, Pharmacology, 1976, 14, 47.

6. A. Lagana, B. Pardo-Martinez, A. Marino, G. Fago, and M. Bizzarri, Anticancer Res., 1995, 15, 2341; A. Lagana, B. PardoMartinez, A. Marino, G. Fago, and M. Bizzarri, Clin. Chim. Acta, 1995, 243, 165.

7. G. M. S. Mancini, F. W. Verheijen, C. E. M. T. Beerens, M. Reniund, and P. Aula, Dev. Neurosci., 1991, 13, 327.
8. L. Chrostek, B. Cylwik, W. Korcz, A. Krawiec, A. Koput, Z. Supronowicz, and M. Szmitkowski, Alcohol. Clin. Exp. Res., 2007, 31, 996.

9. A. Sugasaki, K. Sugiyasu, M. Ikeda, M. Takeuchi, and S. Shinkai, J. Am. Chem. Soc., 2001, 123, 10239; H. Otsuka, E. Uchimura, H. Koshino, T. Okano, and K. Kataoka, J. Am. Chem. Soc., 2003, 125, 3493; Y. Yang, R. T. Lewis, J. O. Escobedo, N. N. St. Luce, W. D.

60 Treleaven, R. L. Cook, and R. M. Strongin, Collect. Czech. Chem. Commun., 2004, 69, 1282; T. M. Altamore, P. J. Duggan, and G. Y. Krippner, Bioorg. Med. Chem., 2006, 14, 1126; Reviewed in T. A. Houston, S. M. Levonis, and M. J. Kiefel, Aust. J. Chem., 2007, 60, 811.

65 10. K. Djanashvili, L. Frullano, and J. A. Peters, Chem.-Eur. J., 2005, 11, 4010 .

11. M. Takeuchi, M. Yamamoto, and S. Shinkai, J. Chem. Soc., Chem. Commun., 1997, 1731; M. Yamamoto, M. Takeuchi, and S. Shinkai, Tetrahedron, 1998, 54, 1731.

70 12. S. Patterson, B. D. Smith, and R .E. Taylor, Tetrahedron Lett., 1998, 39, 3111.

13. T. Asano, H. Nakamura, Y. Uehara, and Y. Yamamoto, ChemBioChem, 2004, 5, 483.

14. G. Springsteen, and B. Wang, Tetrahedron, 2002, 58, 5291; J. Yan, G. Springsteen, S. Deeter, and B. Wang, Tetrahedron, 2004, 60, 11205;

15. T. D. James, K. R. A. S. Samankumara, and S. Shinkai, Nature, 1995, 374, 345 .

16. C. W. Gray, Jr., and T. A. Houston, J. Org. Chem., 2002, 67, 5426.

80 17. J. Zhao, T. M. Fyles, and T. D. James, Angew. Chem. Int. Ed., 2004, 43, 3461. See also, S. L. Wiskur, J. J. Lavigne, A. Metzger, S. L. Tobey, V. Lynch and E. V. Anslyn, Chem.-Eur. J., 2004, 10, 3792.

18. M. Takeuchi, S. Yoda, T. Imada, and S. Shinkai, Tetrahedron, 1997 , 53, 8335 .

85 19. C. W. Gray, Jr., L. L. Johnson, Jr., B. T. Walker, R. Pluorde, M. Sleevi, and T. A. Houston, Bioorg. Med. Chem. Lett., 2005, 15, 5416.

20. While the association of 2 for sialic acid at pH $6.2\left(\mathrm{~K}_{\mathrm{a}}=\right.$ ca. $\left.30 \mathrm{M}^{-1}\right)$ is greater than phenylboronic acid at $\mathrm{pH} 7.4\left(\mathrm{~K}_{\mathrm{a}}=21 \mathrm{M}^{-1}\right.$, see ref. 14), a more rigid diboronate receptor should greatly improve affinity (see W. Yang, H. He, and D. G. Drueckhammer, Angew. Chem. Int. Ed., 2001, 40, 1714). 
